\title{
Infusion of butyrate affects plasma glucose, butyrate, and $\beta$-hydroxybutyrate but not plasma insulin in lactating dairy cows
}

\author{
K. J. Herrick, ${ }^{* 1}$ A. R. Hippen, ${ }^{* 2}$ K. F. Kalscheur, ${ }^{* 3,4}$ D. J. Schingoethe, ${ }^{*}$ S. D. Ranathunga, ${ }^{5}$ J. L. Anderson, ${ }^{*}$ \\ S. C. Moreland, $\dagger$ and J. E. van Eysł \\ *Dairy and Food Science Department, South Dakota State University, Brookings 57007 \\ †Nutriad Inc., Hampshire, IL 60140 \\ ‡GANS Inc., 24 Av. De la Guillemotte, 78112 Fourqueux, France
}

\begin{abstract}
The objective of this study was to investigate the effects on plasma metabolites and rumen traits when butyrate was infused into the rumen or abomasum of lactating cows. Jugular catheters were inserted into 5 ruminally fistulated Holstein cows $[94.2 \pm 26.3$ DIM; $717 \pm 45 \mathrm{~kg}$ of body weight (BW); mean $\pm \mathrm{SD}$ ] in a 5 $\times 5$ Latin square with 3 -d periods. Cows were infused for $24 \mathrm{~h}$ with 1 of 5 treatments: water $(\mathrm{CON}), 1 \mathrm{~g} / \mathrm{kg}$ of BW of butyrate infused into either the abomasum (A1) or rumen (R1), or $2 \mathrm{~g} / \mathrm{kg}$ of $\mathrm{BW}$ of butyrate infused into either the abomasum or rumen. Sodium butyrate was the source of butyrate and $\mathrm{NaCl}$ was added to the $\mathrm{CON}, \mathrm{A} 1$, and $\mathrm{R} 1$ treatments to provide the same amount of sodium as supplied by the sodium butyrate treatment in the 2-g treatments. Plastisol flanges were inserted into the abomasum to allow infusion to the abomasum and peristaltic pumps provided continuous infusion at $9.3 \mathrm{~mL} / \mathrm{min}$ for all treatments. The concentration of $\mathrm{NaCl}$ and sodium butyrate was varied in the infusate to provide the correct infusion amount. Rumen fluid samples were collected at $-2,-1,0,1,2$, $3,4,6,8,12,18,24,28$, and $32 \mathrm{~h}$ relative to start of infusion. Serial blood samples were collected at $-2,-1$, $0,0.5,1,2,3,4,6,8,12,18,24,26,28$, and $32 \mathrm{~h}$ relative to start of infusion. Compared with CON, infusing butyrate increased both plasma butyrate and plasma $\beta$-hydroxybutyrate (BHB), whereas plasma glucose
\end{abstract}

\footnotetext{
Received September 14, 2017.

Accepted December 5, 2017.

${ }^{1}$ Present address: POET Nutrition, 4506 N. Lewis Ave., Sioux Falls, SD 57110.

${ }^{2}$ Deceased.

${ }^{3}$ Corresponding author: kenneth.kalscheur@ars.usda.gov

${ }^{4}$ Present address: US Dairy Forage Research Center, USDA-ARS, 1925 Linden Drive, Madison, WI 53706.

${ }^{5}$ Present address: University of Wisconsin-Madison, 1675 Observatory Drive, Madison, WI 53706.
}

decreased. Increasing butyrate infusion from 1 to $2 \mathrm{~g}$ increased plasma butyrate, tended to decrease plasma glucose, and tended to increase plasma BHB. Compared with abomasal infusion, rumen infusion of butyrate increased rumen butyrate, did not affect plasma glucose, and tended to increase plasma BHB. Treatment had no effect on plasma insulin. Results demonstrated that site of infusion and amount of butyrate affected several plasma metabolites when butyrate was infused in lactating dairy cows over a period of $24 \mathrm{~h}$.

Key words: butyrate, rumen, abomasum, infusion

\section{INTRODUCTION}

Butyrate supplementation beneficially affects growth, digestibility, feed efficiency, and intestinal health in preruminants (Guilloteau et al., 2009; Górka et al., 2011) and nonruminants (Bach Knudsen et al., 2003; Blouin et al., 2011). However, rapid conversion of butyrate to ketone bodies (Heitmann et al., 1987; Holtenius and Holtenius, 1996) makes it difficult to elucidate the effect of supplemental butyrate in mature ruminants with a functioning rumen (Kleiber et al., 1954; Huhtanen et al., 1993; Górka et al., 2017). As a result, far less data investigating supplemental butyrate exist for lactating dairy cows. Additional research would help identify potential benefits of dietary butyrate for mature ruminants.

Most of the previous research investigating effects of butyrate in ruminants focused on the relationship of butyrate to metabolic disorders (Nielsen and Ingvartsen, 2004) and poor forage fermentation profile (Senel and Owen, 1967). However, a few researchers have focused on other aspects of butyrate metabolism in ruminants. Early work by Kleiber et al. (1954) and Black et al. (1961) showed that butyrate influences several metabolites related to glucose and lipid metabolism. Seymour et al. (2005) reported that milk yield was most highly related to rumen concentrations of butyrate when 
comparing concentrations of acetate, propionate, and butyrate in the rumen. Recent work demonstrated that butyrate elevates plasma ketone bodies and alters plasma glucose and insulin when infused as a single dose into the rumen (Herrick et al., 2017).

However, singly dosing butyrate does not depict a practical application. Animal response to a more continuous supply of butyrate similar to inclusion in a TMR needs to be investigated to determine the potential commercial value of butyrate supplementation. Previous work reported that plasma metabolites responded very quickly to a single infusion of butyrate and effects disappeared rapidly (Herrick et al., 2017). We hypothesized that infusing butyrate over a longer period would result in elevated plasma metabolites such as ketone bodies. Furthermore, we hypothesized that infusing butyrate into the abomasum compared with into the rumen would affect certain plasma metabolites to a greater extent because of less alimentary ketogenesis by rumen epithelium.

Accordingly, our objectives for this study included measuring plasma metabolite responses when lactating dairy cows received a 24 -h butyrate infusion of either 1 or $2 \mathrm{~g}$ of butyrate per $\mathrm{kg}$ of BW into either the rumen or abomasum. Results from this study will help further explain butyrate metabolism as well as identify potential applications for sodium butyrate supplementation in mature ruminants.

\section{MATERIALS AND METHODS}

Animal care and use was approved by the South Dakota State University Institutional Animal Care and Use Committee. Five multiparous Holstein cows with rumen cannula averaging (mean $\pm \mathrm{SD}$ ) $36.3 \pm 3.1 \mathrm{~kg}$ milk/d, $94.2 \pm 26.3 \mathrm{DIM}$, and $717 \pm 45.1 \mathrm{~kg}$ of BW at the start of the study were used in a $5 \times 5$ Latin square design with 3 -d periods. Cows were randomly assigned to 1 of 5 infusion treatments. Cows were infused for 24 h with 1 of 5 treatments: water $(\mathbf{C O N}), 1 \mathrm{~g} / \mathrm{kg}$ of BW of butyrate infused into either the abomasum (A1) or rumen $(\mathbf{R} 1)$, or $2 \mathrm{~g} / \mathrm{kg}$ of BW of butyrate infused into either the abomasum (A2) or rumen (R2). Concentrations of butyrate were based on previous research that suggested a maximum butyrate supplementation of 2 $\mathrm{g} / \mathrm{kg}$ of BW (Herrick et al., 2017). Sodium butyrate (Nutriad Inc., Hampshire, IL) was the source of butyrate. Butyrate concentration was calculated as $77.53 \%$ of the sodium butyrate product based on molecular weight (110.09 g/mol for sodium butyrate and 87.098 $\mathrm{g} / \mathrm{mol}$ for butyrate) and purity $(98 \%)$. Sodium chloride was added to the CON, A1, and R1 treatments to provide equal amounts of sodium as the 2 -g treatments.
Sodium chloride was infused into the rumen for the CON treatment.

Flanges and abomasum insertion devices were prepared according to Gressley et al. (2006) and inserted into the abomasum of all 5 cows on the day before starting the experiment. Two 1-cm-diameter holes were drilled into each of the 5 cannula stoppers (\#1EZ, Bar Diamond, Parma, ID). Two tubes (catalog \#1416910A, Thermo Scientific Nalgene 980 Braided Clear Tubing, Thermo Fisher Scientific, Waltham, MA) were used for the infusion into the rumen and abomasum. One tube had the abomasal flange attached to one end with the other end of the tube inserted through one of the holes in the rumen cannula stopper. A separate tube was inserted into the other hole in the cannula stopper and used for the rumen infusion. A 2- to 3-cm length of tube was cut and cyclohexanone was used to fuse this with the infusion tube around the top and bottom of the rumen cannula and the top and bottom of the abomasal flange to act as a washer. The length of the abomasal infusion tube was sufficient to reach from the abomasum to the rumen cannula with approximately 30 to $40 \mathrm{~cm}$ of slack. The rumen infusion tube was cut to a length so that the end of the tube was placed in the middle of the fiber mat. Infusion tubes and abomasal flanges remained in place for the duration of the study. The tube that was not being used for treatment administration during each period was sealed with tape to prevent excessive escape or input of gasses to the rumen or abomasum.

Individual peristaltic pumps (APT SP200CS.104 Fixed Flow Cased Peristaltic Pump, 18RPM/120V, $3.0 \mathrm{~mm}$ Silicone Tubing with Standard Case Enclosure, Small Pumps, Antioch, CA) were used for treatment administration. Individual solutions of sodium butyrate and $\mathrm{NaCl}$ were prepared for each cow during each period. Approximately $14 \mathrm{~L}$ of solution per cow was prepared, which allowed for sufficient volume for $24 \mathrm{~h}$ of constant infusion at a rate of $9.3 \mathrm{~mL} / \mathrm{min}$. Infusion rate remained constant for all cows, and accordingly, the concentration of sodium butyrate in the solution was determined by the treatment assignment and the weight of the cow.

Cows were housed in the metabolism barn at the South Dakota State University Dairy Research and Training Facility, located in Brookings, for the duration of the experiment. All cows were moved into individual metabolism stalls $2 \mathrm{~d}$ before beginning period 1 for adaptation. Body weight of each cow was recorded at the start of period 1 and this BW was used to calculate treatment mixes for all periods. Cows remained in the stalls for the entire experiment. During d 2 and 3, cows were allowed access to a bedded pack for a period of 2 
$\mathrm{h} / \mathrm{d}$. Cows did not have access to feed during this time, but water was available.

The herd diet was mixed once daily but fed as a TMR $2 \times$ a day $(0800$ and $1800 \mathrm{~h}$ ) and was provided to allow for at least $10 \%$ daily refusal. The herd diet [formulated to meet NRC (2001) requirements for a high producing (36 kg of milk per day) mature Holstein cow (Table 1)] contained on a DM basis $31.2 \%$ corn silage, $17.6 \%$ ground corn, $16.4 \%$ alfalfa haylage, $7.9 \%$ alfalfa hay, $6.4 \%$ dried distillers grains with solubles, $4.5 \%$ whole cottonseed, $3.2 \%$ liquid molasses, $3.0 \%$ soybean meal, $2.3 \%$ heat-treated soybean meal, $2.1 \%$ wheat middlings, $0.8 \%$ blood meal, $0.5 \%$ liquid fat, $0.3 \%$ dry fat, and $3.8 \%$ of additives and a mineral-vitamin premix. Feed intakes and refusals were recorded daily. Samples of the TMR and alfalfa haylage were sampled for every period. Individual haylage samples were sampled because of the possibility of elevated butyrate content resulting from poor fermentation. Samples were immediately frozen at $-20^{\circ} \mathrm{C}$ for later nutrient analysis and VFA profile determination.

Cows were milked $3 \times$ daily at 0600,1400 , and $2000 \mathrm{~h}$ and milk weights were recorded using a hand scale. Milk samples were collected from each cow for each milking of each period. Milk was composited on a weight basis proportional to yield for each cow for d 2 and 3 of each period and separated into 2 aliquots. Samples from each milking for $\mathrm{d} 1$ and one sample from the individual cow milk composites from d 2 and 3 were sent to Heart of America DHIA Laboratory (Manhattan, KS) for analysis. Mid-infrared spectroscopy (Bentley 2000 Infrared Milk Analyzer, Bentley Instruments, Chaska, MN; AOAC International, 2002) was used to analyze milk fat, protein, and lactose, whereas MUN concentration was determined using chemical methodology based on a modified Berthelot reaction (ChemSpec 150 Analyzer, Bentley Instruments). Somatic cell counts were determined using a flow cytometer laser (Somacount 500, Bentley Instruments, AOAC International, 2002). Four percent FCM was calculated using the following equation: $[0.4 \times$ milk yield $(\mathrm{kg})]+[15 \times$ fat yield $(\mathrm{kg})]$ (Orth, 1992). The other milk sample and composite samples were frozen at $-20^{\circ} \mathrm{C}$ for later milk fatty acid analysis.

Rumen fluid was collected via cannulas at $-2,-1,0$, $1,2,3,4,6,8,12,18,24,28$, and $32 \mathrm{~h}$ relative to start of infusion. Samples of rumen fluid were taken from the cranial, central, and caudal portions of the rumen via a filtered probe and tube attached to a $50-\mathrm{mL}$ syringe. Ten milliliters of rumen fluid was added to a vial containing $2 \mathrm{~mL}$ of $25 \%$ (wt/vol) metaphosphoric acid and immediately frozen at $-20^{\circ} \mathrm{C}$ until VFA analysis. An additional $10 \mathrm{~mL}$ of rumen fluid to be used for ammonia
Table 1. Chemical composition of TMR

\begin{tabular}{lc}
\hline Item (\% of DM unless otherwise indicated) & TMR \\
\hline DM (\% of diet) & $57.1(2.22)^{1}$ \\
CP & $16.0(0.20)$ \\
NDF & $30.9(1.47)$ \\
ADF & $22.5(0.36)$ \\
Ether extract & $5.26(0.33)$ \\
Sugar & $3.04(0.64)$ \\
Starch $_{\text {NE }}^{2}$ (Mcal $\left./ \mathrm{kg}\right)$ & $25.3(1.02)$ \\
Ash & $1.61(0.02)$ \\
Ca & $7.84(0.26)$ \\
P & $1.17(0.04)$ \\
$\mathrm{Mg}$ & $0.47(0.02)$ \\
$\mathrm{K}$ & $0.37(0.01)$ \\
$\mathrm{S}$ & $1.42(0.03)$ \\
$\mathrm{Cl}$ & $0.25(0.01)$ \\
\hline
\end{tabular}

${ }^{1}$ Numbers in parentheses represent $\mathrm{SD} ; \mathrm{n}=5$.

${ }^{2}$ Ohio Agricultural Research and Development Center summative energy equations.

analysis was added to a separate vial containing $200 \mu \mathrm{L}$ of $50 \%$ (vol $/ \mathrm{vol}$ ) $\mathrm{H}_{2} \mathrm{SO}_{4}$ and frozen at $-20^{\circ} \mathrm{C}$. Rumen $\mathrm{pH}$ was measured using a digital $\mathrm{pH}$ meter (Waterproof $\mathrm{pH}$ Tester 30, Oaktron Instruments, Vernon Hills, IL) immediately after collection and before mixing rumen fluid with metaphosphoric acid.

Jugular catheters were inserted the day before starting period 1. Catheter patency was checked the day before starting each period. If it was determined the catheter needed to be replaced, the old catheter was removed and a replacement was inserted in the opposite jugular vein. Cows were carefully monitored for infection or irritation around the catheter insertion site and if there were any adverse reactions, the catheter was replaced. A 14 gauge $\times 14.0 \mathrm{~cm}$ extended-use IV catheter (catalog \#J458A, Jorgensen Laboratories Inc., Loveland, CO) was inserted and superglue was used to secure the catheter to the hide. A 76.2-cm macrobore extension set (List \#12656-28, Hospira, Lake Forest, IL) was attached to the catheter and $4 \mathrm{~mL}$ of a $20 \mathrm{U} /$ $\mathrm{mL}$ concentration of $\mathrm{Na}$ heparin was flushed through the catheter to prevent clotting. A stopper (reference \#418020, B. Braun Medical Inc., Bethlehem, PA) was secured to the end of the extension set and elastikon tape (3M, St. Paul, MN) was wrapped around the catheter and extension set to prevent accidental removal by the animal.

Blood samples were collected at $-2,-1,0,0.5,1$, $2,3,4,6,8,12,18,24,26,28$, and $32 \mathrm{~h}$ relative to start of infusion. A $12-\mathrm{mL}$ Kendall monoject syringe with a Luer Lock tip (Covidien, Mansfield, MA) was used to withdraw the blood sample from the catheter. An initial 10-mL volume of blood was withdrawn and discarded before collecting the sample. Sufficient blood 
was withdrawn to fill 2 tubes containing $\mathrm{K}_{2}$-EDTA (16 $\times 100 \mathrm{~mm} ; 18 \mathrm{mg}$ of $\mathrm{K}_{2}$-EDTA; $10 \mathrm{~mL}$; catalog no. 0265732; BD Vacutainer, Franklin Lakes, NJ) and 1 tube containing glycolytic inhibitors $(13 \times 100 \mathrm{~mm}$; $15 \mathrm{mg}$ of $\mathrm{NaFl}, 12 \mathrm{mg}$ of $\mathrm{K}$ oxalate; $6 \mathrm{~mL}$; cat. no. 0268848; BD Vacutainer). Catheters were flushed with a $10 \mathrm{mg} / \mathrm{mL}$ concentration of Na citrate when the interval between sampling was less than $6 \mathrm{~h}$ in order to prevent heparin-induced activation of lipoprotein lipase and subsequent elevation of blood free fatty acid concentrations. Catheters were flushed with $\mathrm{Na}$ heparin $(20 \mathrm{U} / \mathrm{mL})$ when the interval between sampling was greater than $6 \mathrm{~h}$ as well as once daily during $\mathrm{d} 2$ and 3 of each period.

Blood samples were immediately placed on ice and then centrifuged at 2,000 $\times g$ for $20 \mathrm{~min}$ at $4^{\circ} \mathrm{C}$. Plasma from the collection tube with glycolytic inhibitors was separated and frozen at $-20^{\circ} \mathrm{C}$ for later glucose analysis. Plasma from the collection tube with $\mathrm{K}_{2}$-EDTA was separated and frozen at $-20^{\circ} \mathrm{C}$ for later analysis of free fatty acids, insulin, and VFA. A portion of the plasma from the collection tube containing $\mathrm{K}_{2}$-EDTA was frozen at $-80^{\circ} \mathrm{C}$ for later analysis of $\mathrm{BHB}$.

\section{Laboratory Analyses}

Total mixed ration and alfalfa haylage samples from each period were submitted to Dairyland Labs (Arcadia, WI) for chemical analysis. Dry matter was determined after drying an approximately 2 -g sample at $105^{\circ} \mathrm{C}$ for 3 h (NFTA Method 2.1.4; Shreve et al., 2006). Crude protein was determined by combustion analysis (AOAC International, 2002; method \#990.03). The procedure of Mertens (2002) was used to determine NDF. Amylase and sulfite were used and analyses were on an ash-free basis. Acid detergent fiber was determined using AOAC International (2002) method \#973.18, ether extract using AOAC International (2002) method \#920.39, and ash using AOAC International (2002) method \#942.05. Starch was determined according to Bach Knudsen (1997). Sugar concentration was determined by measuring total ethanol-soluble carbohydrates, and minerals were analyzed using an inductively coupled plasmid technique (AOAC International, 2002; method \#985.01). Volatile fatty acid concentration of forages and TMR was determined according to Canale et al. (1984).

Rumen fluid samples containing $\mathrm{H}_{2} \mathrm{SO}_{4}$ were thawed, centrifuged for $20 \mathrm{~min}$ at $2,000 \times g$ at $4^{\circ} \mathrm{C}$, and analyzed for ammonia $\mathrm{N}$ according to a modified procedure of Chaney and Marbach (1962). The modifications included reducing the sodium hypochlorite from 2.1 to $0.87 \mathrm{~g} / \mathrm{L}$ and measuring the absorbance at a wavelength of $630 \mathrm{~nm}$. Rumen fluid samples containing metaphosphoric acid were thawed, centrifuged at 2,000 $\times g$ for 20 min at $4^{\circ} \mathrm{C}$, and analyzed for acetate, propionate, butyrate, isobutyrate, isovalerate, and valerate. Concentrations of rumen VFA were measured using GC (model 6890, Hewlett-Packard, Avondale, PA) and separated on a $15 \mathrm{~m} \times 0.25 \mathrm{~mm}$ i.d. column (Nukol, 17926-01C, Supelco Inc., Bellefonte, PA). The split ratio of 100:1 in the injector port was at a temperature of $250^{\circ} \mathrm{C}$ with flow rate of $1.3 \mathrm{~mL} / \mathrm{min}$ of He. The column and detector temperature were maintained at 140 and $250^{\circ} \mathrm{C}$, respectively.

Plasma samples were analyzed for glucose [Liquid Glucose (Oxidase) Reagent Set, Pointe Scientific Inc., Canton, MI; Trinder, 1969], free fatty acids [HR Series free fatty acids -HR (2) Microtiter Procedure; Wako Diagnostics, Richmond, VA; Johnson and Peters, 1993], and BHB [EnzyChrom Ketone Body Assay Kit (EKBD-100); BioAssay Systems; Hayward, CA; Williamson et al., 1962]. Insulin was measured using Coat-A-Count RIA kit (PITKIN-8; Siemens, Washington, DC; Ehrhardt et al., 2001). The insulin assay demonstrated an inter-assay variation of $11.54 \%$ and an intra-assay variation of $4.83 \%$. Plasma was prepared for VFA analysis as described by Oba and Allen (2003) with a few modifications to accommodate GC analysis. Instead of crotonic acid as an internal standard, $2.0 \mathrm{~g}$ of 2-ethylbutyrate (Sigma-Aldrich \#109959, St. Louis, MO) was added to the cupric sulfate solution. Additionally, $50 \mu \mathrm{L}$ of $50 \%$ (wt/vol) metaphosphoric acid was added instead of concentrated $\mathrm{H}_{2} \mathrm{SO}_{4}$ after the samples were thawed for the first time. Plasma VFA were analyzed with the same equipment as previously described for rumen VFA. A split-less injection port $\left(280^{\circ} \mathrm{C}\right)$ was configured with a purge time and flow of $0.10 \mathrm{~min}$ and $10 \mathrm{~mL} / \mathrm{min}$ of $\mathrm{He}$, respectively. The flame ionization detector was maintained at $300^{\circ} \mathrm{C}$, and initial oven temperature was $100^{\circ} \mathrm{C}$ for $6 \mathrm{~min}$ and then was increased by $5^{\circ} \mathrm{C} / \mathrm{min}$ to $120^{\circ} \mathrm{C}$ where it was held for 5 min.

Milk fatty acids were prepared as butyl esters according to Abdelqader et al. (2009) with the following modifications. Milk samples were centrifuged at 3,000 $\times$ $g$ for $30 \mathrm{~min}$ at $0^{\circ} \mathrm{C}$. Fifteen to $20 \mathrm{mg}$ of the fat pad was scraped off and placed into $13 \times 100-\mathrm{mm}$ Pyrex extraction tubes with Teflon-lined screw caps. To each of the tubes, $500 \mu \mathrm{L}$ of butanol and $25 \mu \mathrm{L}$ of internal standard (2-tridecenoic acid, Nu-Chek Prep Inc., Elysian, MN) were added. Samples were slowly vortexed while adding $50 \mu \mathrm{L}$ of acetyl chloride. The tubes were gassed with $\mathrm{N}_{2}$ and then heated on a dry heating block at $60^{\circ} \mathrm{C}$ for 90 min. After samples cooled to room temperature, $5 \mathrm{~mL}$ of $6 \% \mathrm{~K}_{2} \mathrm{CO}_{3}$ was added and the samples were vortexed 
for $30 \mathrm{~s}$. Following this step, $1 \mathrm{~mL}$ of hexane was added to each tube and the samples were again vortexed and then placed in a centrifuge at 3,000 $\times g$ for $25 \mathrm{~min}$ at $4^{\circ} \mathrm{C}$. The bottom layer was aspirated and discarded. The remaining hexane layer was washed $3 \times$ with $5 \mathrm{~mL}$ of distilled deionized water and centrifuged at $3,000 \times$ $g$ for $25 \mathrm{~min}$ at $4^{\circ} \mathrm{C}$. The upper layer containing hexane and butyl esters of fatty acids was removed and placed in injection vials for GC analysis.

Prepared samples were analyzed using GC (model 6890, Hewlett-Packard, Palo Alto, CA). The injector port was at $230^{\circ} \mathrm{C}$ with a split ratio of $100: 1$ and $\mathrm{He}$ as a carrier at a column flow-rate of $2.0 \mathrm{~mL} / \mathrm{min}$. The column was $100 \mathrm{~m}$ in length with an inside diameter of $0.25 \mathrm{~mm}$ (Supelco 2560, Supelco Inc.). Initial temperature of the column was $50^{\circ} \mathrm{C}$ and held for $5 \mathrm{~min}$, then increased to $145^{\circ} \mathrm{C}$ at a rate of $5^{\circ} \mathrm{C} / \mathrm{min}$. It was held at $145^{\circ} \mathrm{C}$ for $30 \mathrm{~min}$, then increased to $190^{\circ} \mathrm{C}$ at $10^{\circ} \mathrm{C} / \mathrm{min}$ to hold the temperature for $30 \mathrm{~min}$. Finally, the temperature was increased at $5^{\circ} \mathrm{C} / \mathrm{min}$ to $210^{\circ} \mathrm{C}$ and held at this temperature for $40 \mathrm{~min}$. Individual fatty acids were identified by order of elution and comparison to known, commercially prepared reference standards (GLC-606 and GLC-566, Nu-Chek Prep Inc.).

\section{Mathematical and Statistical Analyses}

All data were analyzed by the MIXED procedure in SAS (SAS version 9.2, SAS Institute Inc., Cary, NC). The model for feed intake, milk yield, and milk composition was $\mathrm{Y}=$ treatment + day + (treatment $\times$ day) + cow $+\mathrm{e}$, where $\mathrm{Y}$ was the variable of interest and day was the day of treatment. Cow was a random effect, and e was the residual error. The model for plasma and rumen traits were $\mathrm{Y}=$ treatment + hour + (treatment $\times$ hour $)+\mathrm{e}$, where $\mathrm{Y}$ was the variable of interest, the random effect was cow, and e was the residual error. Hour was considered a repeated measure. Ante-dependence, first-order dependence, compound symmetry, unstructured, first order autoregressive, and Toeplitz covariance structures were all evaluated. The variancecovariance error structure was ante-dependence variance, which was selected based on the lowest Akaike information criterion fit statistic (Littell et al., 2006). The model for milk fatty acids was $\mathrm{Y}=$ treatment + period, where $\mathrm{Y}$ was each of the individual fatty acids and the random effect was cow.

Least squares means are reported for each variable and statistical significance of main effects was declared at $P \leq 0.05$ and tendencies were discussed at $0.05<$ $P \leq 0.10$. Significant interactions are identified in the Results and tables. Mean comparisons were performed using the Tukey test. Contrasts for CON versus butyr- ate treatments (A1, A2, R1, and R2), $1 \mathrm{~g}$ of butyrate treatments (A1 and $\mathrm{R} 1$ ) versus $2 \mathrm{~g}$ of butyrate treatments (A2 and R2), rumen infusion treatments (R1 and R2) versus abomasum infusion treatments (A1 and A2), and the interaction of site of infusion (rumen vs. abomasum) and treatment dose (1 vs. 2 g) were included in the statistical analysis for all measures.

\section{RESULTS}

\section{Diet and Production Response}

Cows adapted well to the metabolism stalls and exhibited no signs of discomfort. Two cows (one cow assigned treatment A2 during period 1 and a second cow assigned to treatment R2 during period 4) developed mastitis; however, both recovered quickly so we included their rumen and plasma data in our analyses. For most measures, animal response to treatment occurred quickly after treatment began (Figures 1, 2, and

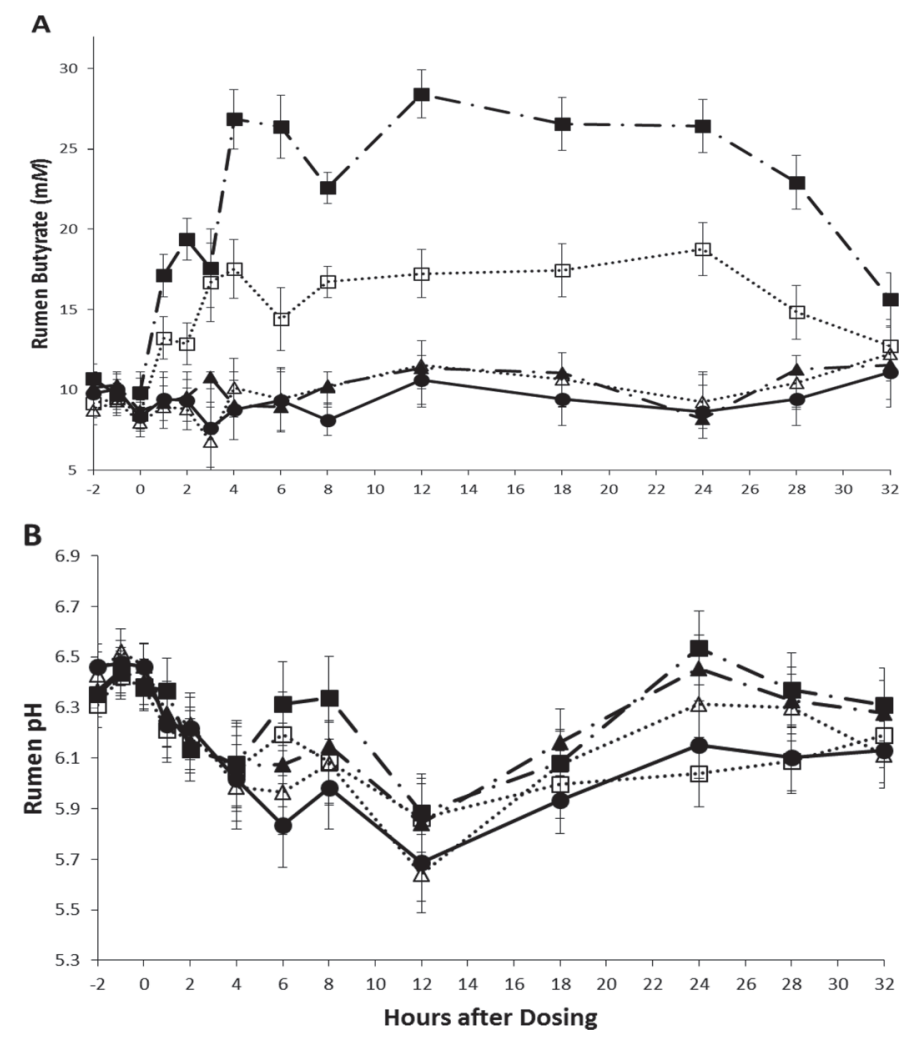

Figure 1. Least squares means of rumen butyrate (A) and rumen $\mathrm{pH}$ (B) from lactating cows ruminally infused with $\mathrm{NaCl}(-\bullet-)$, ruminally infused with $1.0 \mathrm{~g}$ of butyrate $/ \mathrm{kg}$ of BW $(\cdots \square \cdots)$, ruminally infused with $2.0 \mathrm{~g}$ of butyrate $/ \mathrm{kg}$ of BW $(-\boldsymbol{\square} \cdot)$, abomasally infused with $1.0 \mathrm{~g}$ of butyrate $/ \mathrm{kg}$ of $\mathrm{BW}(\cdots \Delta \cdots)$, or abomasally infused with

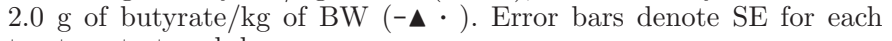
treatment at each hour. 
A

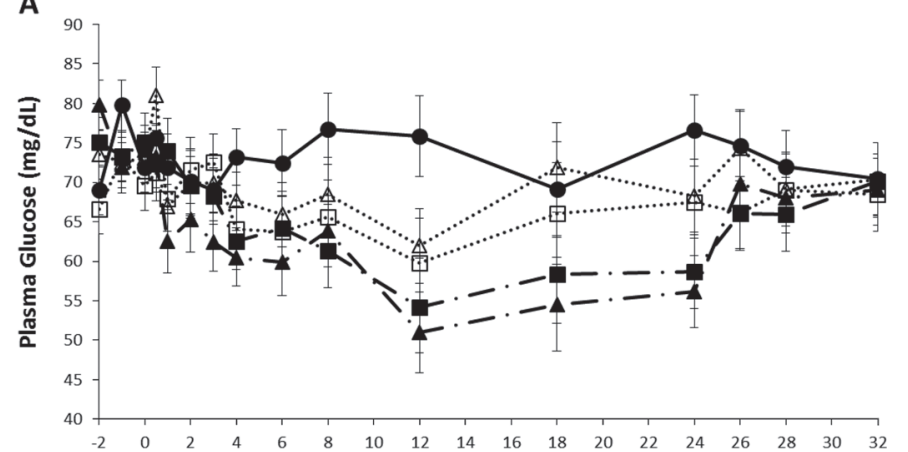

B

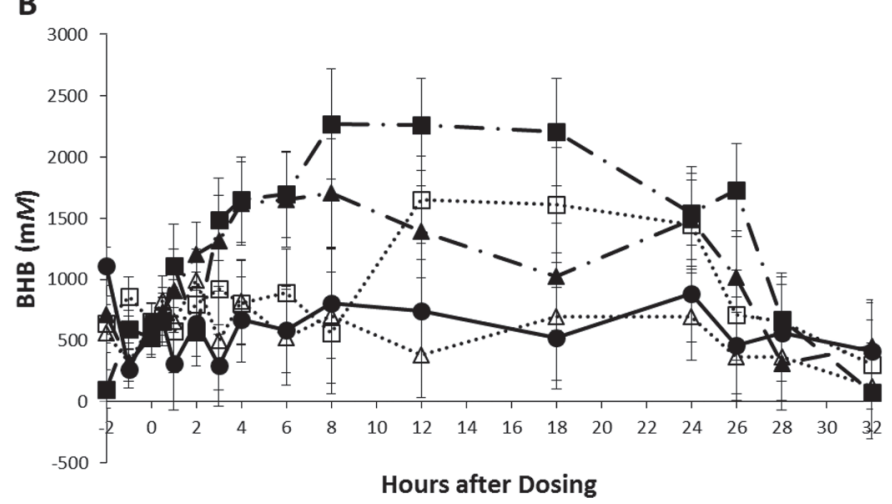

Figure 2. Least squares means of plasma glucose (A) and plasma BHB (B) from lactating cows ruminally infused with $\mathrm{NaCl}(-\bullet-)$, ruminally infused with $1.0 \mathrm{~g}$ of butyrate $/ \mathrm{kg}$ of $\mathrm{BW}(\cdots \square \cdots)$, ruminally infused with $2.0 \mathrm{~g}$ of butyrate $/ \mathrm{kg}$ of BW (-口 • ), abomasally infused with $1.0 \mathrm{~g}$ of butyrate $/ \mathrm{kg}$ of BW $(\cdots \Delta \cdots)$, or abomasally infused with $2.0 \mathrm{~g}$ of butyrate $/ \mathrm{kg}$ of BW (-ム $)$. Error bars denote SE for each treatment at each hour.

3) and disappeared shortly after treatment stopped. As a result, it appears the time between treatment periods served as an adequate wash-out period.

Table 1 contains the analyzed chemical composition of the diet. In addition to chemical composition, we analyzed both the TMR and haylage samples for butyric acid to account for butyrate beyond our treatment administration. Laboratory analysis did not detect additional butyrate (data not shown). Fermentation of molasses from the base diet may have resulted in additional butyrate (Martel et al., 2011); however, all cows received the same base diet and, as a result, similar amounts of dietary butyrate.

The short duration of the study prevented us from inferring either a production response or lack of production response directly related to treatment. Nevertheless, we analyzed and reported intake, production, and milk component data because these data provide a better description of experimental conditions (Table 2). Cows across all treatments consumed (mean \pm SEM)
$18.6 \pm 3.3 \mathrm{~kg}$ of DM per day and produced $36.3 \pm$ $3.8 \mathrm{~kg}$ of $3.5 \%$ FCM per day. Dry matter intake values include the weight of sodium butyrate and $\mathrm{NaCl}$ infused into either the rumen or abomasum. Butyrate treatment did not alter the yield or percentage of any milk components; however, the concentration of $C 4: 0$ and the short-chain fatty acids in the milk increased with butyrate infusion in either the rumen or the abomasum (Table 3). Infusing $2 \mathrm{~g}$ into either the rumen or abomasum increased several of the milk short-chain fatty acids compared with infusing only $1 \mathrm{~g}$ of butyrate. Furthermore, infusing butyrate into the abomasum also increased milk short-chain fatty acids compared with infusing butyrate into the rumen. Infusing $1 \mathrm{~g}$ compared with $2 \mathrm{~g}$ of butyrate resulted in greater concentrations of the long-chain fatty acids C18:1 cis-9 and C18:2 cis$9, c i s-12$. The concentrations of these fatty acids also increased in milk from cows infused with butyrate in the rumen compared with the abomasum.

\section{A}

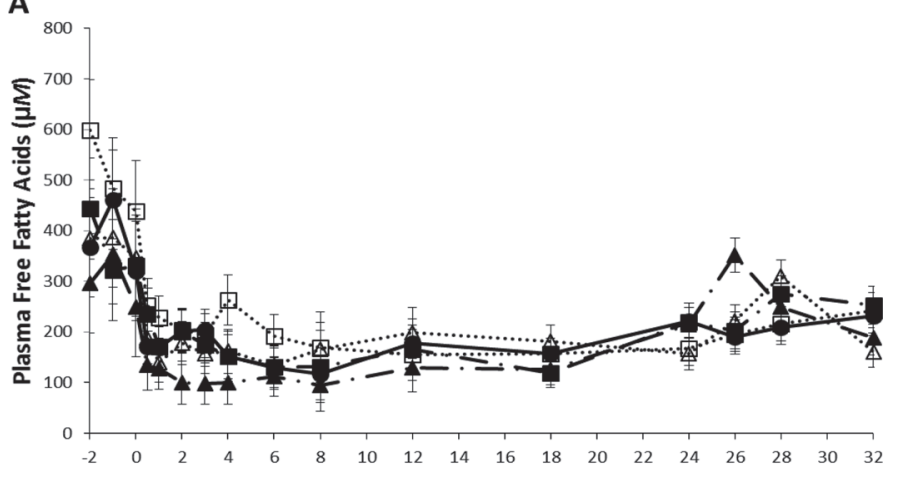

B

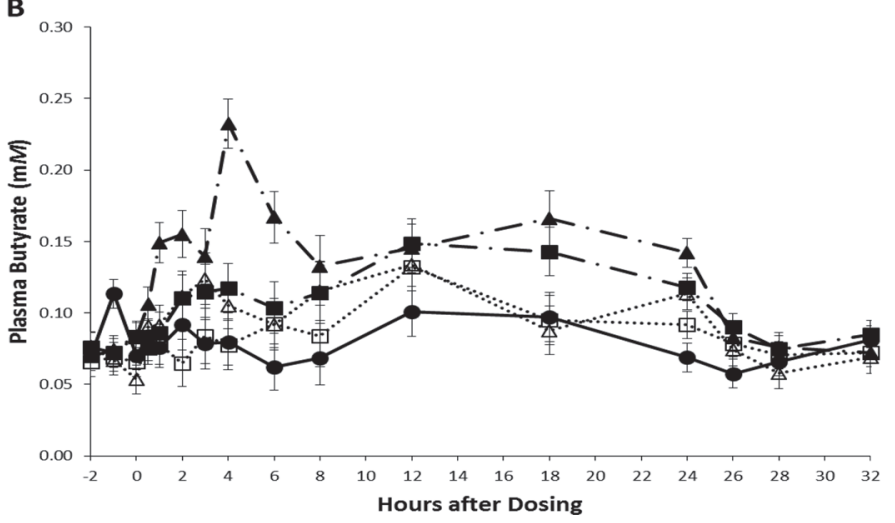

Figure 3. Least squares means of plasma free fatty acids (A) and plasma butyrate (B) from lactating cows ruminally infused with $\mathrm{NaCl}$ $(-\bullet-)$, ruminally infused with $1.0 \mathrm{~g}$ of butyrate/kg of BW $(\cdots \square \cdots)$, ruminally infused with $2.0 \mathrm{~g}$ of butyrate $/ \mathrm{kg}$ of $\mathrm{BW}(-\mathbf{0} \cdot)$, abomasally infused with $1.0 \mathrm{~g}$ of butyrate/ $\mathrm{kg}$ of $\mathrm{BW}(\cdots \Delta \cdots)$, or abomasally infused with $2.0 \mathrm{~g}$ of butyrate $/ \mathrm{kg}$ of BW $(-\boldsymbol{\Lambda} \cdot)$. Error bars denote SE for each treatment at each hour. 
Table 2. Least squares means of production measures in lactating Holstein cows infused with sodium chloride (CON) or 1 or $2 \mathrm{~g}$ of butyrate/ $\mathrm{kg}$ of $\mathrm{BW}$

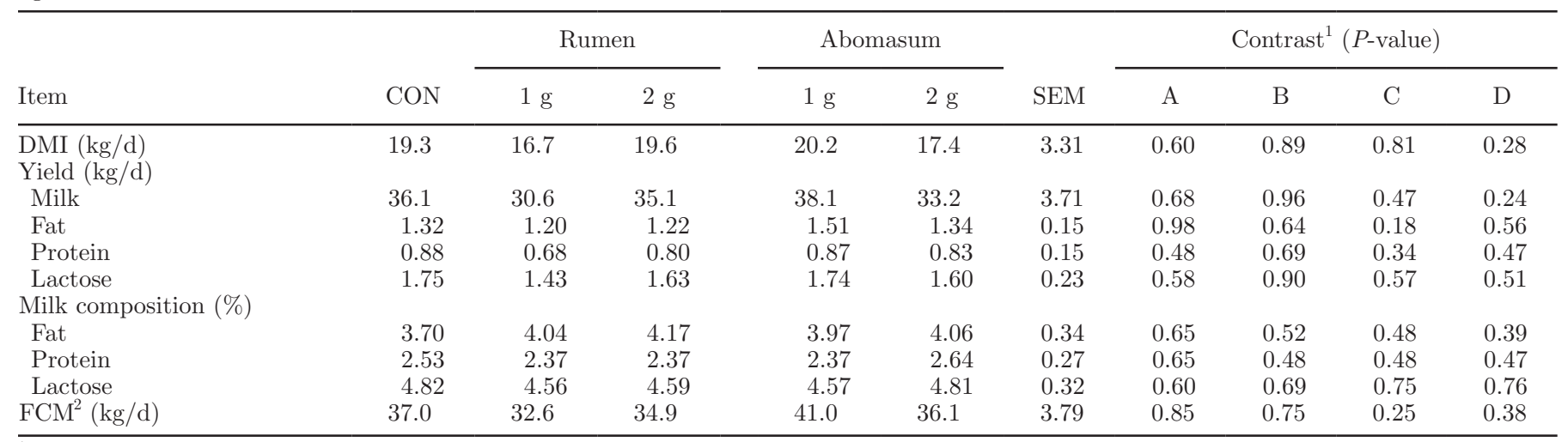

${ }^{1}$ Contrasts: $\mathrm{A}=\mathrm{CON}$ vs. butyrate; $\mathrm{B}=1$ vs. $2 \mathrm{~g}$; $\mathrm{C}=$ rumen vs. abomasum; $\mathrm{D}=$ interaction of infusion site (rumen vs. abomasum) and treatment dose (1 vs. $2 \mathrm{~g})$.

${ }^{2} 4 \% \mathrm{FCM}=[0.4 \times$ milk yield $(\mathrm{kg})]+[15 \times$ fat yield $(\mathrm{kg})]$.

\section{Rumen Measures}

As expected, concentration and proportion of ruminal butyrate increased $(P<0.01)$ with infusion of butyrate into the rumen versus the abomasum (Table 4). Rumen butyrate concentration increased $63.3 \%$ in cows administered the $\mathrm{R} 1$ treatment and $135.9 \%$ in cows given the $\mathrm{R} 2$ treatment compared with the aver- age rumen butyrate concentration for cows given the $\mathrm{CON}, \mathrm{A} 1$, and $\mathrm{A} 2$ treatments. A change in rumen butyrate concentration (Figure 1A) started within $2 \mathrm{~h}$ of treatment administration and remained evident for $8 \mathrm{~h}$ after treatment cessation. Furthermore, the proportion of rumen propionate compared with CON decreased $(P$ $=0.05)$ when we administered butyrate to either the rumen or abomasum.

Table 3. Least squares means of milk fatty acids in lactating Holstein cows infused with sodium chloride (CON) or 1 or $2 \mathrm{~g}$ of butyrate/kg of BW

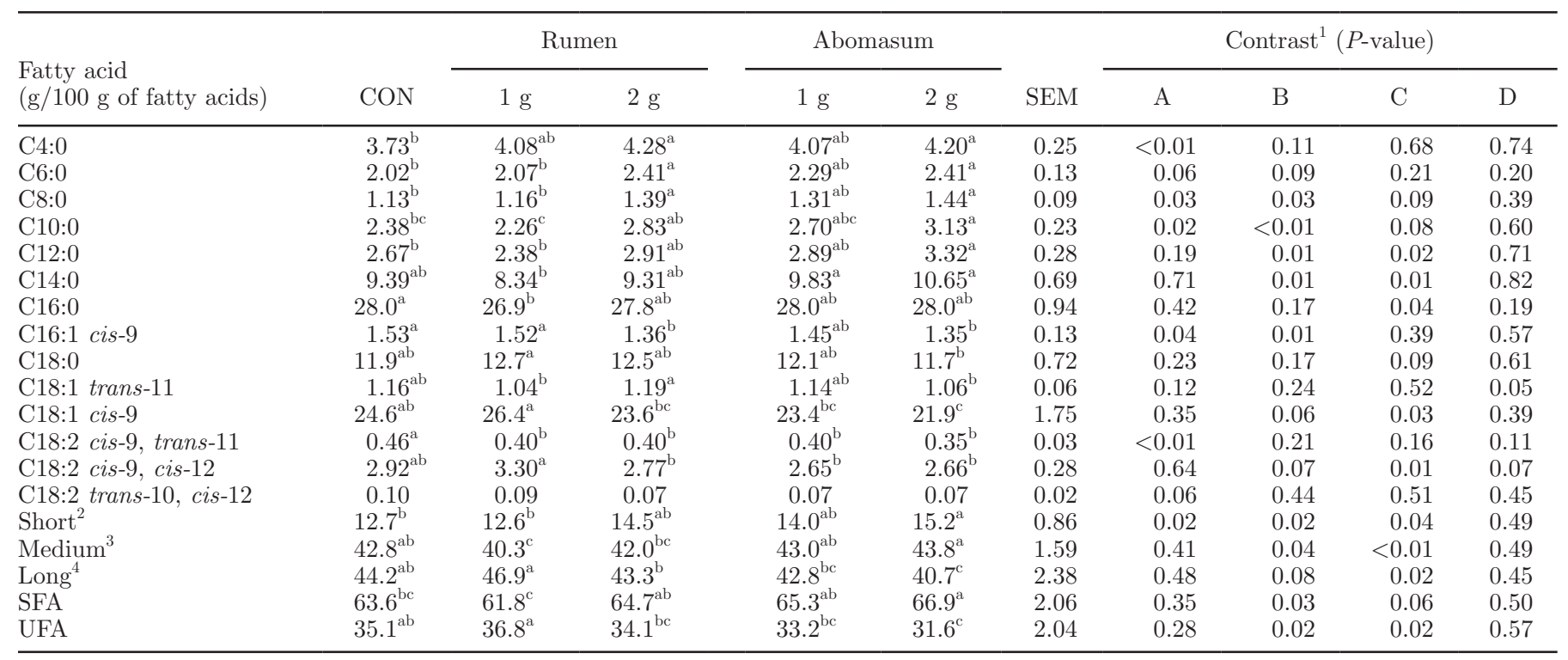

${ }^{\mathrm{a}-\mathrm{c}}$ Means within a row with different superscripts differ $(P<0.05)$.

${ }^{1}$ Contrasts: $\mathrm{A}=\mathrm{CON}$ vs. butyrate; $\mathrm{B}=1$ vs. $2 \mathrm{~g} ; \mathrm{C}=$ rumen vs. abomasum; $\mathrm{D}=$ interaction of site of infusion (rumen vs. abomasum) and treatment dose (1 vs. $2 \mathrm{~g})$.

${ }^{2}$ Short-chain FA (C4:0 to C13:0).

${ }^{3}$ Medium-chain FA (C13:0 to C17:1).

${ }^{4}$ Long-chain FA ( $\geq$ C18:0). 
Table 4. Least squares means of rumen fluid measures in lactating Holstein cows infused with sodium chloride (CON) or 1 or $2 \mathrm{~g}$ of butyrate/ $\mathrm{kg}$ of $\mathrm{BW}$

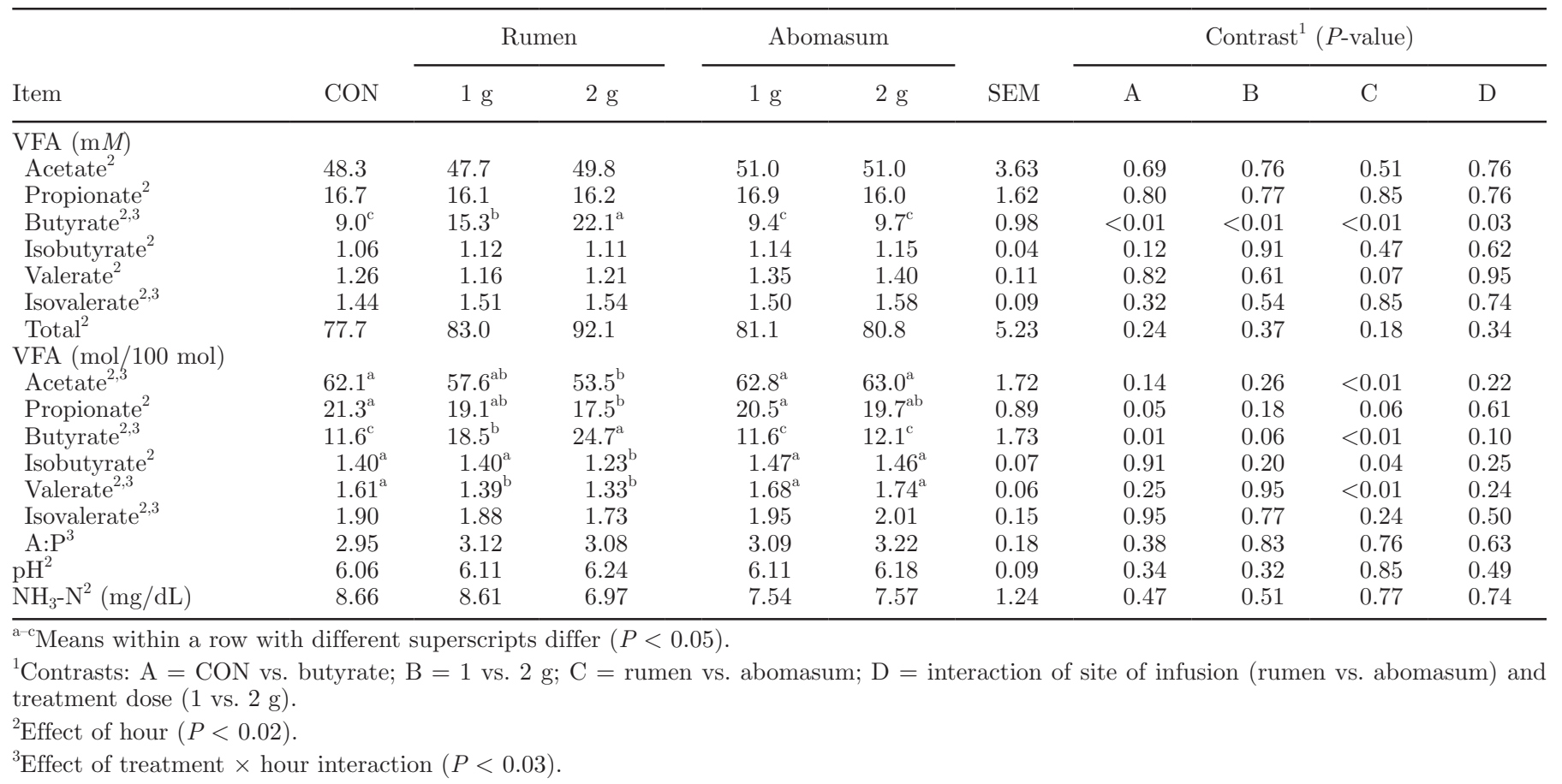

Increasing the amount of butyrate from 1 to $2 \mathrm{~g}$ did not affect any of the rumen VFA except for an increase $(P<0.01)$ in concentration and a trend $(P$ $=0.06$ ) for an increase in the proportion of butyrate. Administering butyrate in the rumen compared with the abomasum increased $(P<0.01)$ the concentration of ruminal butyrate and tended $(P=0.07)$ to decrease the concentration of ruminal valerate. The proportion of ruminal acetate and valerate decreased $(P<0.01)$ with butyrate infusion into the rumen compared with the abomasum. Interestingly, the proportion of rumen valerate decreased $20.5 \%$ in cows infused with butyrate in the rumen versus the abomasum. Also, infusing butyrate into the rumen compared with the abomasum tended $(P=0.06)$ to decrease the proportion of ruminal propionate.

Although least squares means for rumen $\mathrm{pH}$ did not differ $(P>0.05)$ between treatments (Table 4), a clear differentiation between treatments started approximately $4 \mathrm{~h}$ after starting butyrate infusion (Figure 1B). Treatment did not affect rumen $\mathrm{NH}_{3}-\mathrm{N}$ (Table 4).

\section{Plasma Measures}

Butyrate addition to either the rumen or abomasum decreased $(P=0.02)$ plasma glucose compared with the CON treatment (Table 5). Furthermore, greater amounts of infused butyrate tended $(P=0.06)$ to decrease plasma glucose. Response to treatment appeared quickly after treatment administration and returned to baseline shortly after ending treatment infusions (Figure 2A). Plasma glucose started to decrease within 2 $\mathrm{h}$ after administration and was back to pretreatment levels $2 \mathrm{~h}$ after treatment was stopped. We did not observe any effects for plasma glucose related to site of butyrate administration or any interactions between site of infusion and treatment dose $(P>0.10)$. Treatment did not affect $(P>0.10)$ plasma insulin (15.6, 9.1, 18.8, 11.5, and $21.4 \mu \mathrm{IU} / \mathrm{L}$ for $\mathrm{CON}, \mathrm{R} 1, \mathrm{R} 2, \mathrm{~A} 1$, and A2; respectively).

Butyrate increased $(P<0.01)$ plasma BHB. Compared with cows given the CON treatment, the $1-\mathrm{g}$ treatments (R1 and A1) increased plasma BHB 33.4\% and the 2-g treatments (R2 and A2) increased plasma BHB by $118.6 \%$. Administering a greater amount of butyrate increased $(P=0.01)$ plasma BHB; however, site of treatment administration only tended $(P=0.08)$ to affect plasma BHB with rumen administration of butyrate resulting in a slightly greater plasma BHB concentration compared with abomasal infusion. Similar to plasma glucose, plasma BHB increased shortly after beginning treatment (Figure 2B). Treatment did not affect $(P>0.10)$ plasma free fatty acids $(184,220$, 185, 183, and $135 \mu M$ for CON, R1, R2, A1, and A2; respectively) (Figure 3A). 
Except for butyrate, treatment did not affect $(P>$ 0.10) plasma VFA (Table 5). Plasma butyrate increased by $40.6 \%$ compared with CON. Providing $2 \mathrm{~g}$ of butyrate $/ \mathrm{kg}$ of BW compared with $1 \mathrm{~g}$ of butyrate/ $\mathrm{kg}$ of $\mathrm{BW}$ increased plasma butyrate by $36.8 \%$ and administering butyrate to the abomasum increased plasma butyrate by $25.0 \%$ compared with rumen infusion. Plasma butyrate responded very quickly to treatment and was comparable to the pattern of response observed for plasma glucose and BHB (Figure 3B).

\section{DISCUSSION}

\section{Diet and Production Response}

In earlier work from our laboratory (Herrick et al., 2017), we investigated butyrate treatments of 1 or $2 \mathrm{~g}$ of butyrate $/ \mathrm{kg}$ of BW singly infused in the rumen of lactating cows. In that work, we selected a concentration of $2 \mathrm{~g}$ of butyrate $/ \mathrm{kg}$ of $\mathrm{BW}$ as the maximum treatment because we wanted to challenge the cows with a concentration not previously investigated (Krehbiel et al., 1992; Miettinen and Huhtanen, 1996). Cows did not exhibit signs of nervous ketosis in that study; however, plasma BHB concentrations approached thresholds defined by Duffield et al. (1998). As a result, the 2-g treatment may better represent a practical maximum rather than treatment amounts based on butyrate production in the rumen. The lack of symptoms for nervous ketosis observed for cows in the current work further validate our assertion that lactating dairy cows can tolerate short-term butyrate supplementation of 2 $\mathrm{g} / \mathrm{kg}$ of BW.

Dry matter intake averaged less than expected for cows at their age, stage of lactation, BW, and milk pro- duction. Although cows appeared comfortable during the experiment and feed was available throughout the day, the intense sampling schedule as well as the disruption in routine may have resulted in reduced appetite. Huhtanen et al. (1997) observed a similar response in DMI and also attributed the response to sampling procedure. Westreicher-Kristen and Susenbeth (2017) included a short discussion on this topic and suggested the design of the infusion device may impair flow of digesta to the abomasum. The device we used (Gressley et al., 2006), remained in the abomasum because of the diameter of the flange inserted into the abomasum. Holes placed in the flange according to the recommendations of Gressley et al. (2006) allowed digesta to flow through the abomasum; however, we recognize the diameter of the flange may have still limited passage.

Production responses to butyrate infusion studies vary (Huhtanen et al., 1993; Miettinen and Huhtanen, 1996; Huhtanen et al., 1998); however, researchers often report increased milk fat yield or percentage when supplementing butyrate. Huhtanen et al. (1993) reported greater milk fat and protein concentration and increased milk and protein yield when substituting a 3:1 acetate to propionate ratio of VFA with increasing concentrations of butyrate up to $600 \mathrm{~g} / \mathrm{d}$. In a similar type of study, Miettinen and Huhtanen (1996) replaced up to $900 \mathrm{~g} / \mathrm{d}$ of propionate with butyrate on an energetic basis. In that study, treatment did not affect milk yield, but milk fat concentration and yield increased as butyrate supplementation increased.

In the current study, butyrate infusion affected shortchain fatty acids and in particular C4:0. This response intrigues us because of the potential for supplying butyrate to humans through milk. Research has demonstrated butyrate can protect the brain and enhance

Table 5. Least squares means of plasma metabolites in lactating Holstein cows infused with sodium chloride (CON) or 1 or $2 \mathrm{~g}$ of butyrate/ $\mathrm{kg}$ of BW

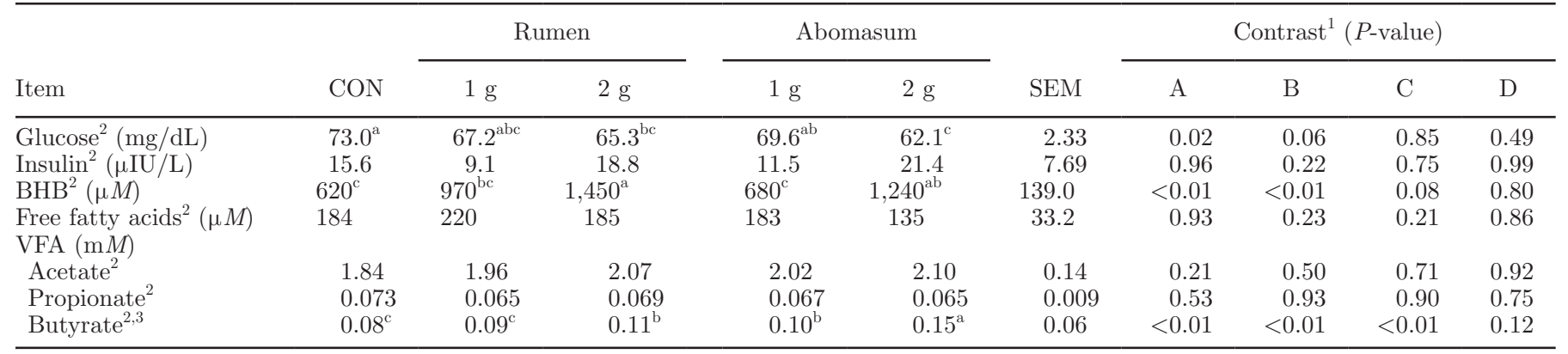

\footnotetext{
${ }^{\mathrm{a}-\mathrm{c}}$ Means within a row with different superscripts differ $(P<0.05)$.

${ }^{1}$ Contrasts: $\mathrm{A}=\mathrm{CON}$ vs. butyrate; $\mathrm{B}=1$ vs. $2 \mathrm{~g} ; \mathrm{C}=$ rumen vs. abomasum; $\mathrm{D}=$ interaction of site of infusion (rumen vs. abomasum) and treatment dose (1 vs. $2 \mathrm{~g})$.

${ }^{2}$ Effect of hour $(P<0.03)$.

${ }^{3}$ Effect of treatment $\times$ hour interaction $(P<0.01)$.
} 
plasticity in neurological disease models (Bourassa et al., 2016), and as a result, butyrate-enriched milk or milk products could serve as a potential human supplement. Although feeding butyrate to lactating dairy cows increased $\mathrm{C} 4: 0$ in the milk fat, benefits to humans may be negligible because of the small absolute amount. Furthermore, because butyrate has a strong odor, elevated butyrate may negatively affect the taste or smell of the milk, which may limit consumer acceptance.

\section{Rumen Measures}

Rumen VFA. Ruminal butyrate increased when we infused butyrate into the rumen but not when we infused butyrate into the abomasum. Furthermore, the $\mathrm{R} 2$ infusion resulted in a similar magnitude increase in ruminal butyrate compared with the $\mathrm{R} 1$ infusion when expressed as a concentration $(1.89 \times)$ or proportion $(2.08 \times)$. These responses validate our technique for treatment administration and abomasal flange placement.

Administrating butyrate over a 24-h period resulted in less of a peak in ruminal butyrate than our previous study in which we singly infused butyrate into the rumen (Herrick et al., 2017). The 1- and 2-g treatments in the previous study (Herrick et al., 2017) resulted in ruminal butyrate peaks of 80.3 and $226.1 \mathrm{~m} M$, respectively. Cows infused with butyrate in the rumen for the current study had ruminal butyrate peaks of only 18.8 and $28.4 \mathrm{mM}$ for the $1-$ and 2 -g treatments, respectively. Interestingly, within $4 \mathrm{~h}$ of starting treatment in the current study, ruminal butyrate concentration in cows ruminally infused with butyrate had already reached the greatest concentration observed throughout the 24 -h period.

The proportion of ruminal valerate decreased with either concentration (R1 or R2) of butyrate infused into the rumen. This agrees with previous studies that reported a decrease in ruminal valerate related to supplemental butyrate (Kristensen et al., 2000; Herrick et al., 2017). The rapid metabolism of both butyrate and valerate (Kristensen et al., 2000) by ruminal epithelium could explain this response. Another hypothesis proposed by Kristensen and Harmon (2004) suggests the decrease in valerate relates to the fact that valerate catabolizes to propionyl $\mathrm{CoA}$, a compound that contributes less to ketogenic pathways than other metabolites. As a result, the possibility exists that ketotic conditions related to butyrate administration result in a preferential shift in metabolic pathways.

Rumen $\boldsymbol{p H}$. In our previous study (Herrick et al., 2017), butyrate elevated rumen $\mathrm{pH}$ compared with con- trol cows. Increased absorption of butyrate from the rumen may have initiated this effect (Müller et al., 2002; Penner et al., 2009; Aschenbach et al., 2011), and this may explain the effects on rumen $\mathrm{pH}$ we observed with the rumen treatments in the current study. However, infusing butyrate into the abomasum also resulted in a slight shift in rumen $\mathrm{pH}$ compared with the control. Rémond et al. (1993) reported increased ruminal blood flow with ruminal injections of butyrate. The possibility exists that increased blood flow could have improved VFA absorption efficiency and subsequently affected rumen $\mathrm{pH}$ in the current research.

\section{Plasma Measures}

Glucose and Insulin. The response in plasma glucose from our study agrees with previous research (Neogrady et al., 1989; Huhtanen et al., 1993; Miettinen and Huhtanen, 1996). Early research by Kleiber et al. (1954) concluded that the response of butyrate on plasma glucose is consistent with the participation of butyrate on net synthesis of carbohydrates. Other researchers (Black et al., 1961; Menahan et al., 1967) used labeled $\mathrm{C}$ to support these early observations. Later, Beauvieux et al. (2008) observed a net synthesis of glycogen in rats force-fed butyrate.

Other researchers who observed no plasma glucose response (DeFrain et al., 2006) or decreased plasma glucose (DeFrain et al., 2004) in cows fed lactose as a source of butyrate hypothesized that BHB may regulate gluconeogenic enzymes. Still others (Demigne et al., 1986) reported that propionate conversion to glucose was inhibited in sheep hepatocytes by the addition of $2 \mathrm{mM}$ butyrate. Aiello et al. (1989) supported these results when they reported that a $1.25 \mathrm{mM}$ concentration of butyrate reduced propionate uptake by as much as $46 \%$ in sheep hepatocytes. It seems likely butyrate has the potential to affect several pathways related to glucose metabolism.

Not observing a concomitant response in insulin related to plasma glucose in the current study contradicted previous research (Sano et al., 1995; Herrick et al., 2017; Zarrin et al., 2017). Previously, singly dosing butyrate into the rumen resulted in a trend for greater plasma insulin (Herrick et al., 2017). In the current study, we expected a similar if not more pronounced response in plasma insulin because of the 24-h infusion times. This would have allowed additional time for the animal to adapt to butyrate administration.

It appears insulin response to butyrate may depend upon several factors such as amount of butyrate, physiological state of the animal, and possibly, the duration of the butyrate administration. Sano et al. (1995) 
reported a dose-dependent response in insulin during intravenous $n$-butyrate infusion to sheep. Plasma insulin did not change until $n$-butyrate was infused at a rate of at least $2 \mu \mathrm{mol}$ per $\mathrm{kg}$ of $\mathrm{BW}$ per minute. This treatment amount resulted in plasma butyrate concentration increasing to a lesser amount than we observed in our study. However, in the Sano et al. (1995) study, researchers intravenously infused butyrate for only 30 $\min$.

$\boldsymbol{B H B}$. The increase in plasma BHB from infusing butyrate into the rumen agrees with the previous literature and supports observations that rumen epithelium rapidly convert butyrate to ketone bodies (Holtenius and Holtenius, 1996; Müller et al., 2002). Butyrate infused into the abomasum would circumvent alimentary ketogenesis by rumen epithelium and result in less plasma BHB. Since the 2-g treatments would have saturated the rumen epithelial enzymes responsible for alimentary ketogenesis with butyrate (Kristensen et al., 2000), we anticipated less of a difference between the 1- and 2-g treatments.

Although the abomasal treatments tended to have less plasma BHB compared with the rumen treatments, the plasma BHB concentration for cows administered $2 \mathrm{~g}$ of butyrate in the abomasum still approached the perceived threshold for dairy cattle. Duffield et al. (1998) has suggested that plasma BHB concentrations greater than $1.4 \mathrm{mM}$ place the lactating cow at greater risk for metabolic diseases and displaced abomasum. However, elevated plasma BHB related to metabolic disorders arise from a disruption in liver function or excessive body fat mobilization. The current study represents a different cause for elevated plasma BHB and as a result, previously defined plasma BHB thresholds may not apply when infusing or continuously feeding a source of butyrate.

Plasma VFA. Infusing butyrate into either the rumen or abomasum increased plasma butyrate. The increase in plasma butyrate we observed for the abomasal infusions compared with the ruminal infusions supported our hypothesis of differences in butyrate absorption based on infusion site. The data suggest both methods of administering butyrate effectively increase plasma butyrate. However, a greater amount of butyrate is needed in the rumen to equal the response seen with a lesser treatment amount in the abomasum.

\section{CONCLUSIONS}

Infusing butyrate over a period of $24 \mathrm{~h}$ in the rumen or abomasum affected several rumen traits and plasma metabolites. This suggests that the benefits of butyrate observed in monogastrics or preruminants may also be possible in mature ruminants with a functioning rumen. However, differences between infusion in the rumen and infusion in the abomasum suggest that commercial applications for a rumen-protected butyrate product may offer advantages. Providing butyrate directly to the abomasum compared with the rumen increased plasma butyrate while at the same time reduced plasma BHB. This minimizes concerns over potential health concerns related to elevated ketone bodies. Butyrate treatment also decreased plasma glucose. Previous research suggests multiple pathways for potential interaction between butyrate and glucose metabolism, which includes effects on enzymes and steps involved with gluconeogenesis. This response requires further investigation to determine if longer term supplementation of butyrate may negatively affect milk production.

\section{ACKNOWLEDGMENTS}

The authors thank Nutriad Inc. (Hampshire, IL) for their generous financial support of this research. Special appreciation is also extended to the graduate students from the South Dakota State University Dairy Science department for their assistance with sampling and animal care.

\section{REFERENCES}

Abdelqader, M. M., A. R. Hippen, K. F. Kalscheur, D. J. Schingoethe, and A. D. Garcia. 2009. Isolipidic additions of fat from corn germ, corn distillers grains, or corn oil in dairy cow diets. J. Dairy Sci. 92:5523-5533. https://doi.org/10.3168/jds.2008-1867.

Aiello, R. J., L. E. Armentano, S. J. Bertics, and A. T. Murphy. 1989. Volatile fatty acid uptake and propionate metabolism in ruminant hepatocytes. J. Dairy Sci. 72:942-949. https://doi.org/10.3168/jds .S0022-0302(89)79187-6.

AOAC International. 2002. Official Method of Analysis. 17th ed. in Association of Official Analytical Chemists. Gaithersburg, MD.

Aschenbach, J. R., G. B. Penner, F. Stumpff, and G. Gabel. 2011. Ruminant Nutrition Symposium: Role of fermentation acid absorption in the regulation of ruminal pH. J. Anim. Sci. 89:1092-1107. https://doi.org/10.2527/jas.2010-3301.

Bach Knudsen, K. E. 1997. Carbohydrate and lignin contents of plant materials used in animal feeding. Anim. Feed Sci. Technol. 67:319338. https://doi.org/10.1016/S0377-8401(97)00009-6.

Bach Knudsen, K. E., A. Serena, N. Canibe, and K. S. Juntunen. 2003. New insight into butyrate metabolism. Proc. Nutr. Soc. 62:81-86. https://doi.org/10.1079/PNS2002212.

Beauvieux, M. C., H. Roumes, N. Robert, H. Gin, V. Rigalleau, and J. L. Gallis. 2008. Butyrate ingestion improves hepatic glycogen storage in the re-fed rat. BMC Physiol. 8:19-31. https://doi.org/ 10.1186/1472-6793-8-19.

Black, A. L., M. Kleiber, and A. M. Brown. 1961. Butyrate metabolism in the lactating cow. J. Biol. Chem. 236:2399-2403.

Blouin, J. M., G. Penot, M. Collinet, M. Nacfer, C. Forest, P. LaurentPuig, X. Coumoul, R. Barouki, C. Benelli, and S. Bortoli. 2011. Butyrate elicits a metabolic switch in human colon cancer cells by targeting the pyruvate dehydrogenase complex. Int. J. Cancer 128:2591-2601. https://doi.org/10.1002/ijc.25599.

Bourassa, M. W., I. Alim, S. J. Bultman, and R. R. Ratan. 2016. Butyrate, neuroepigenetics and the gut microbiome: Can a high fiber 
diet improve brain health? Neurosci. Lett. 625:56-63. https://doi .org/10.1016/j.neulet.2016.02.009.

Canale, A., M. Valente, and A. Ciotti. 1984. Determination of volatile carboxylic acids $\left(\mathrm{C}_{1}-\mathrm{C}_{5 \mathrm{i}}\right)$ and lactic acid in aqueous acid extracts of silage by high performance liquid chromatography. J. Sci. Food Agric. 35:1178-1182. https://doi.org/10.1002/jsfa.2740351106.

Chaney, A. L., and E. P. Marbach. 1962. Modified reagents for determination of urea and ammonia. Clin. Chem. 8:130-132.

DeFrain, J. M., A. R. Hippen, K. F. Kalscheur, and D. J. Schingoethe. 2004. Feeding lactose increases ruminal butyrate and plasma B-hydroxybutyrate in lactating dairy cows. J. Dairy Sci. 87:24862494. https://doi.org/10.3168/jds.S0022-0302(04)73373-1.

DeFrain, J. M., A. R. Hippen, K. F. Kalscheur, and D. J. Schingoethe. 2006. Feeding lactose to increase ruminal butyrate and the metabolic status of transition dairy cows. J. Dairy Sci. 89:267-276. https://doi.org/10.3168/jds.S0022-0302(06)72091-4.

Demigne, C., C. Yacoub, C. Remesy, and P. Fafournoux. 1986. Propionate and butyrate metabolism in rat or sheep hepatocytes. Biochim. Biophys. Acta 875:535-542. https://doi.org/10.1016/0005 $-2760(86) 90074-3$

Duffield, T. F., D. Sandals, K. E. Leslie, K. Lissemore, B. W. McBride, J. H. Lumsden, P. Dick, and R. Bagg. 1998. Efficacy of monensin for the prevention of subclinical ketosis in lactating dairy cows. J. Dairy Sci. 81:2866-2873. https://doi.org/10.3168/jds.S0022 $-0302(98) 75846-1$.

Ehrhardt, R. A., R. M. Slepetis, A. W. Bell, and Y. R. Boisclair. 2001. Maternal leptin is elevated during pregnancy in sheep. Domest. Anim. Endocrinol. 21:85-96. https://doi.org/10.1016/S0739 $-7240(01) 00108-4$.

Górka, P., Z. M. Kowalski, P. Pietrzak, A. Kotunia, W. Jagusiak, J. J. Holst, P. Guilloteau, and R. Zabielski. 2011. Effect of method of delivery of sodium butyrate on rumen development in newborn calves. J. Dairy Sci. 94:5578-5588. https://doi.org/10.3168/jds .2011-4166

Górka, P., B. Śliwiński, J. Flaga, J. Wieczorek, M. M. Godlewski, E. Wierzchoś, R. Zabielski, and Z. M. Kowalski. 2017. Effect of butyrate infusion into the rumen on butyrate flow to the duodenum, selected gene expression in the duodenum epithelium, and nutrient digestion in sheep. J. Anim. Sci. 95:2144-2155. https://doi.org/10 $.2527 /$ jas. 2016.1218 .

Gressley, T. F., S. M. Reynal, J. J. Comenero, G. A. Broderick, and L. E. Armentano. 2006. Technical note: Development of a tool to inset abomasal infusion lines into dairy cows. J. Dairy Sci. 89:39653967. https://doi.org/10.3168/jds.S0022-0302(06)72438-9.

Guilloteau, P., R. Zabielski, J. C. David, J. W. Blum, J. A. Morisset, M. Biernat, J. Woliński, D. Laubitz, and Y. Hamon. 2009. Sodium-butyrate as a growth promoter in milk replacer formula for young calves. J. Dairy Sci. 92:1038-1049. https://doi.org/10 $.3168 /$ jds.2008-1213.

Heitmann, R. N., D. J. Dawes, and S. C. Sensenig. 1987. Hepatic ketogenesis and peripheral ketone body utilization in the ruminant. J. Nutr. 117:1174-1180.

Herrick, K. H., A. R. Hippen, K. F. Kalscheur, D. J. Schingoethe, D. P. Casper, S. C. Moreland, and J. E. van Eys. 2017. Singledose infusion of sodium butyrate, but not lactose, increases plasma $\beta$-hydroxybutyrate and insulin in lactating dairy cows. J. Dairy Sci. 100:757-768. https://doi.org/10.3168/jds.2016-11634.

Holtenius, P., and K. Holtenius. 1996. New aspects of ketone bodies in energy metabolism of dairy cows: A review. J. Vet. Med. A Physiol. Pathol. Clin. Med. 43:579-587. https://doi.org/10.1111/j .1439-0442.1996.tb00491.x.

Huhtanen, P., P. G. Brotz, and L. D. Satter. 1997. Omasal sampling technique for assessing fermentative digestion in the forestomach of dairy cows. J. Anim. Sci. 75:1380-1392. https://doi.org/10 $.2527 / 1997.7551380 \mathrm{x}$.

Huhtanen, P., H. Miettinen, and M. Ylinen. 1993. Effect of increasing ruminal butyrate on milk yield and blood constituents in dairy cows fed a grass silage-based diet. J. Dairy Sci. 76:1114-1124. https://doi.org/10.3168/jds.S0022-0302(93)77440-8.

Huhtanen, P. J., R. Blauwiekel, and I. Saastamoinen. 1998. Effects of intraruminal infusions of propionate and butyrate with two differ- ent protein supplements on milk production and blood metabolites in dairy cows receiving grass silage-based diet. J. Sci. Food Agric. 77:213-222. https://doi.org/10.1002/(SICI)1097-0010(199806)77:2 \%3C213:AID-JSFA28\%3E3.0.CO;2-6.

Johnson, M. M., and J. P. Peters. 1993. Technical note: An improved method to quantify nonesterified fatty acids in bovine plasma. J. Anim. Sci. 71:753-756. https://doi.org/10.2527/1993.713753x.

Kleiber, M., A. L. Black, M. A. Brown, J. Luick, C. F. Baxter, and B. M. Tolbert. 1954. Butyrate as a precursor for milk constituents in the intact dairy cow. J. Biol. Chem. 210:239-247.

Krehbiel, C. R., D. L. Harmon, and J. E. Schneider. 1992. Effect of increasing ruminal butyrate on portal and hepatic nutrient flux in steers. J. Anim. Sci. 70:904-914. https://doi.org/10.2527/1992 $.703904 x$.

Kristensen, N. B., and D. L. Harmon. 2004. Effect of increasing ruminal butyrate absorption on splanchnic metabolism of volatile fatty acids absorbed from the washed reticulorumen of steers. J. Anim. Sci. 82:3549-3559.

Kristensen, N. B., S. G. Pierzynowski, and A. Danfaer. 2000. Net portal appearance of volatile fatty acids in sheep intraruminally infused with mixtures of acetate, propionate, isobutyrate, butyrate, and valerate. J. Anim. Sci. 78:1372-1379. https://doi.org/10 $.2527 / 2000.7851372 \mathrm{x}$

Littell, R. C., G. A. Milliken, W. W. Stroup, R. D. Wolfinger, and O. O. Schabenberger. 2006. SAS for Mixed Models. 2nd ed. SAS Institute Inc., Cary, NC.

Martel, C. A., E. C. Titgemeyer, L. K. Mamedova, and B. J. Bradford. 2011. Dietary molasses increases ruminal $\mathrm{pH}$ and enhances ruminal biohydrogenation during milk fat depression. J. Dairy Sci. 94:3995-4004. https://doi.org/10.3168/jds.2011-4178.

Menahan, L. A., L. H. Schultz, and W. G. Hoekstra. 1967. Metabolism of butyrate-3-14C in the ruminant under various metabolic states. J. Dairy Sci. 50:1417-1429. https://doi.org/10.3168/jds.S0022 -0302(67)87644-6.

Mertens, D. R. 2002. Gravimetric determination of amylase treated neutral detergent fiber in feeds with refluxing in beakers or crucibles: Collaborative study. J. AOAC Int. 85:1217-1240.

Miettinen, H., and P. Huhtanen. 1996. Effects of the ratio of ruminal propionate to butyrate on milk yield and blood metabolites in dairy cows. J. Dairy Sci. 79:851-861. https://doi.org/10.3168/jds .S0022-0302(96)76434-2.

Müller, F., K. Huber, H. Pfannkuche, J. R. Aschenbach, G. Breves, and G. Gäbel. 2002. Transport of ketone bodies and lactate in the sheep ruminal epithelium by monocarboxylate transporter 1 . Am. J. Physiol. Gastrointest. Liver Physiol. 283:G1139-G1146. https://doi.org/10.1152/ajpgi.00268.2001.

Neogrady, Z., P. Galfi, and F. Kutas. 1989. Effect of intraruminal butyrate infusion on the plasma insulin level in sheep. Acta Vet. Hung. 37:247-253.

Nielsen, N. I., and K. L. Ingvartsen. 2004. Propylene glycol for dairy cows: A review of the metabolism of propylene glycol and its effects on physiological parameters, feed intake, milk production, and risk of ketosis. Anim. Feed Sci. Technol. 115:191-213. https:// doi.org/10.1016/j.anifeedsci.2004.03.008.

NRC. 2001. Nutrient Requirements of Dairy Cattle. 7th rev. ed. Natl. Acad. Press, Washington, DC.

Oba, M., and M. S. Allen. 2003. Effects of corn grain conservation method on feeding behavior and productivity of lactating dairy cows at two dietary starch concentrations. J. Dairy Sci. 86:174183. https://doi.org/10.3168/jds.S0022-0302(03)73598-X.

Orth, R. 1992. Sample day and lactation report. DHIA 200 Fact Sheet A-2. Mid-States DRPC, Ames, IA.

Penner, G. B., J. R. Aschenbach, G. Gäbel, R. Rackwitz, and M. Oba. 2009. Epithelial capacity for apical uptake of short chain fatty acids as a key determinant for intraruminal $\mathrm{pH}$ and the susceptibility to subacute ruminal acidosis in sheep. J. Nutr. 139:1714-1720. https://doi.org/10.3945/jn.109.108506.

Rémond, D., J. P. Chaise, E. Delval, and C. Poncet. 1993. Net transfer of urea and ammonia across the ruminal wall of sheep. J. Anim. Sci. 71:2785-2792. https://doi.org/10.2527/1993.71102785x. 
Sano, H., S. Tano, H. Takahashi, and Y. Terashima. 1995. Dose response of plasma insulin and glucagon to intravenous $n$-butyrate infusion in sheep. J. Anim. Sci. 73:3038-3043. https://doi.org/10 $.2527 / 1995.73103038 x$

Senel, S. H., and F. G. Owen. 1967. Relation of dietary acetic and butyric acids to intake, digestibility, lactation performance, and ruminal and blood levels of certain metabolites. J. Dairy Sci. 50:327-333. https://doi.org/10.3168/jds.S0022-0302(67)87419-8.

Seymour, W. M., D. R. Campbell, and Z. B. Johnson. 2005. Relationships between rumen volatile fatty acid concentrations and milk production in dairy cows: A literature study. Anim. Feed Sci. Technol. 119:155-169. https://doi.org/10.1016/j.anifeedsci.2004 .10.001.

Shreve, B., N. Thiex, and M. Wolf. 2006. NFTA method 2.1.4-Dry matter by oven drying for 3 hours at $105^{\circ} \mathrm{C}$. NFTA Reference Methods. National Forage Testing Association, Omaha, NE.
Accessed Apr. 18, 2017. http://www.foragetesting.org/files/ NFTAReferenceMethodDM-09-18-06.pdf.

Trinder, P. 1969. Determination of glucose in blood using glucose oxidase with an alternative oxygen acceptor. Ann. Clin. Biochem. 6:24-27. https://doi.org/10.1177/000456326900600108.

Westreicher-Kristen, E., and A. Susenbeth. 2017. Technical note: An improved tool to insert lines for abomasal infusion in rumen cannulated cattle. J. Dairy Sci. 100:1951-1954. https://doi.org/10 $.3168 /$ jds.2016-12150.

Williamson, D. H., J. Mellanby, and H. A. Krebs. 1962. Enzymatic determination of $\mathrm{D}(-) \beta$-hydroxybutyrate and acetotacetic acid in blood. Biochem. J. 82:90-96.

Zarrin, M., L. Grossen-Rösti, R. M. Bruckmaier, and J. J. Gross. 2017. Elevation of blood $\beta$-hydroxybutyrate concentration affects glucose metabolism in dairy cows before and after parturition. J. Dairy Sci. 100:2323-2333. https://doi.org/10.3168/jds.2016-11714. 